\title{
PENGARUH NAUNGAN TERHADAP PERTUMBUHAN DAN MUTU BIBIT CEMPAKA WASIAN (Magnolia tsiampaca (Miq.) Dandy) DI PERSEMAIAN
}

\author{
SHADE EFFECT ON GROWTH AND QUALITY OF CEMPAKA WASIAN SEEDLING (Magnolia \\ tsiampaca (Miq.) Dandy) IN NURSERY
}

\author{
Arif Irawan dan Hanif Nurul Hidayah \\ Balai Penelitian dan Pengembangan Lingkungan Hidup dan Kehutanan Manado \\ Jl. Tugu Adipura Raya Kel. Kima Atas Kec. Mapanget Kota Manado \\ Telp : 085100666683 Email : arif_net23@yahoo.com,
}

Diterima: 29 Januari 2017; direvisi: 01 Pebruari 2017; disetujui: 25 April 2017

\begin{abstract}
ABSTRAK
Cempaka wasian (Magnolia tsiampaca (Miq) Dandy)) adalah salah satu jenis tanaman kehutanan yang memiliki nilai ekonomi yang cukup tinggi. Pengembangan cempaka wasian dalam bentuk hutan-hutan rakyat di Provinsi Sulawesi Utara perlu didukung oleh ketersediaan bibit yang berkualitas. Pada umumnya setiap jenis tanaman memiliki pengaruh yang berbeda-beda terhadap cahaya yang diterimanya. Penelitian ini bertujuan untuk mengetahui pengaruh intensitas naungan terhadap pertumbuhan bibit cempaka wasian di persemaian. Rancangan percobaan yang digunakan dalam penelitian ini adalah rancangan acak lengkap. Perlakuan yang dicobakan antara lain naungan dengan kerapatan $25 \%$ (intensitas cahaya \pm 37.350 lux), naungan dengan kerapatan $50 \%$ (intensitas cahaya \pm 19.100 lux) dan naungan dengan kerapatan $75 \%$ (intensitas cahaya \pm 8.018 lux). Hasil penelitian menunjukkan bahwa perlakuan dengan tingkat kerapatan naungan $50 \%$ (Intensitas cahaya \pm 19.100 lux) memberikan pengaruh terbaik terhadap pertumbuhan dan mutu bibit di persemaian.
\end{abstract}

Kata kunci: cempaka wasian, naungan, bibit

\begin{abstract}
Cempaka wasian (Magnolia tsiampaca (Miq) Dandy)) is one tree species with high economic value. Cempaka wasian development in the form of community forests in the province of North Sulawesi needs to be supported by the availability of quality seeds. Generally, plant has different effect towards light it received. This study aimed to determine the effect of shade intensity on the growth of seedlings in the nursery. The experimental design used in this research is completely randomized design. The treatments were tested among other shade with a density of $25 \%( \pm 37,350$ lux light intensity), the shade with a density of $50 \%( \pm 19,100$ lux light intensity) and shade with a density of $75 \%$ ( \pm 8,018 lux light intensity). The results showed that treatment with 50\% shade density ( $\pm 19,100$ lux light intensity) gives the best effect on the growth and quality of seedlings in the nursery.
\end{abstract}

Keywords : cempaka wasian, shade, seeds

\section{PENDAHULUAN}

Magnolia tsiampaca (Miq) Dandy adalah salah satu jenis tanaman kehutanan penghasil kayu yang memiliki nilai ekonomi yang cukup tinggi. Kayu ini telah diperdagangkan sejak lama baik dalam bentuk kayu bulat, kayu gergajian dan konstruksi jadi seperti furniture, lemari, pintu, jendela maupun rumah jadi, perahu, panel, alat olahraga, alat musik kolintang dan plywood (Kinho dan Mahfudz, 2011b). Kayu yang juga memiliki nama lokal cempaka ini memiliki kelas awet dan kelas kuat II dengan berat jenis 0,52-0,73 dan kerapatan kayu 500 - 650 kg/m3 (Langi, 2007). Kayu Cempaka merupakan unsur yang wajib ada, pada sebuah rumah tradisional atau rumah panggung (rumah woloan) dan tidak tergantikan oleh jenis kayu lainnya pada beberapa daerah di Minahasa (Kinho dan Irawan, 2011a).

Cempaka wasian tergolong dalam kelas medium growing species. Pertumbuhan jenis tanaman ini pada habitat aslinya dapat mencapai tinggi $60 \mathrm{~m}$ dan diameter 150 - $250 \mathrm{~cm}$ (Kinho dan Mahfudz, 2011b). Lawe et al. (2012) menyatakan bahwa riap rata-rata diameter E. ovalis pada hutan rakyat di daerah Masarang (Kabupaten Minahasa, Sulawesi Utara) adalah $2,25 \mathrm{~cm} /$ tahun sedangkan riap tingginya adalah $1,63 \mathrm{~m} /$ tahun sampai $1,78 \mathrm{~m} /$ tahun. Tegakan cempaka wasian banyak ditemukan hampir pada setiap hutan rakyat, kebun campuran dan hutan keluarga (hutan 
pasini) di Kabupaten Minahasa Utara (sekitar Gunung Klabat), Kota Tomohon (Tara-tara, Pinaras, Gunung Mahawu, dan Gunung Masarang), Kabupaten Minahasa (Kawangkoan, Langowan, Tondano Timur), Kabupaten Minahasa Selatan (Tareran), Kabupaten Bolaang Mongondow (Modayak) (Kinho, 2010).

Pengembangan tanaman kehutanan dalam bentuk hutan rakyat perlu didukung oleh ketersediaan bibit yang berkualitas. Kurniaty et al. (2010) menyatakan bahwa penggunaan bibit berkualitas dapat menghasilkan tegakan dengan tingkat produktifitas yang tinggi. Kualitas bibit di persemaian sangat dipengaruhi oleh faktor genetik dan faktor lingkungan (Hani, 2009). Salah satu faktor lingkungan yang berpengaruh terhadap kualitas bibit adalah faktor intensitas cahaya. Pada umumnya setiap jenis tanaman memiliki pengaruh yang berbeda-beda terhadap cahaya yang diterimanya. Kurniaty (2010) menyatakan bahwa intensitas cahaya yang terlalu rendah akan menghasilkan produk fotosintesis yang tidak maksimal, sedangkan intensitas cahaya yang terlalu tinggi akan berpengaruh terhadap aktivitas selsel stomata daun dalam mengurangi transpirasi sehingga mengakibatkan terhambatnya pertumbuhan tanaman. Oleh karena itu intensitas cahaya optimal sangat diperlukan agar pertumbuhan tanaman dapat maksimal dan dapat menghasilkan bibit yang memiliki kualitas yang baik. Pengaturan intensitas cahaya dapat dilakukan dengan pemberian naungan sehingga dapat melindungi bibit dari cahaya matahari dan suhu yang berlebihan. Naungan juga diperlukan untuk mengurangi evaporasi dan transpirasi sehingga kelembaban media dapat dipertahankan dan tanaman dapat tumbuh dengan baik. Penelitian ini bertujuan untuk mengetahui pengaruh intensitas naungan terhadap pertumbuhan bibit cempaka wasian di persemaian.

\section{METODE PENELITIAN}

Penelitian ini dilaksanakan di Persemaian Permanen BPDAS Tondano Kima Atas yang terletak di Kecamatan Mapanget Kota Manado. Area persemaian berada pada ketinggian $70 \mathrm{~m}$ dpl, dengan suhu rata-rata $34{ }^{\circ} \mathrm{C}$ dan tingkat kelembaban $40 \%$. Penelitian dilaksanakan pada bulan Mei sd.Nopember 2013.

Bahan dan alat yang digunakan dalam penelitian ini adalah benih cempaka wasian ( $M$. tsiampaca), top soil, polybag, paranet, luxmeter, mistar, kaliper dan alat tulis menulis.
Perkecambahan benih cempaka wasian dilakukan pada bak plastik menggunakan media pasir. Perkecambahan benih berlangsung pada 10 (sepuluh) hari setelah penaburan dan bibit siap disapih 1 (satu) minggu setelahnya. Pada awalnya, bibit disapih pada bedengan dengan intensitas naungan yang sama. Selanjutnya saat bibit telah berumur sekitar 1 (satu) bulan, bibit ditempatkan pada bedengan sesuai dengan naungan yang dicobakan.

Pengamatan pertumbuhan tanaman dilakukan pada umur bibit 5 (lima) bulan. Beberapa parameter pertumbuhan yang diamati adalah:

1. Tinggi Bibit

Tinggi bibit cempaka wasian diukur menggunakan mistar. Pengukuran dilakukan mulai dari pangkal batang hingga titik tumbuh bibit.

2. Diameter Batang

Diameter batang diukur menggunakan alat ukur kaliper. Pengukuran dilakukan pada ketinggian 1 (satu) $\mathrm{cm}$ di atas permukaan tanah.

3. Indeks Mutu Bibit (IMB)

Penghitungan indeks kualitas semai menggunakan cara Dickson (1960) dalam Hendromono (1994) dengan rumus :

$\mathrm{IMB}=\frac{\text { Bobot kering batang }(\mathrm{gr})+\text { Bobot kering akar }(\mathrm{gr})}{\frac{\text { Tinggi }(\mathrm{cm})}{\text { Diameter }(\mathrm{cm})}+\frac{\text { Bobot kering batang }(\mathrm{gr})}{\text { Bobot Kering akar }(\mathrm{gr})}}$

\section{Persen Hidup Bibit}

Pengukuran persen hidup bibit dihitung dengan rumus sebagai berikut :

Persen hidup bibit $=\frac{\text { Jumlah bibit yang hidup }}{\text { jumlah bibit total yang disapih }} \times 100 \%$

Rancangan percobaan yang digunakan dalam penelitian ini adalah rancangan acak lengkap. Taraf perlakuan yang dicobakan adalah naungan dengan kerapatan $25 \%$ (IC \pm 37.350 lux), kerapatan $50 \%$ (IC \pm 19.100 lux), dan kerapatan $75 \%$ (IC \pm 8.018 lux). Setiap perlakuan diulang sebanyak 3 (tiga) kali dengan jumlah setiap ulangannya adalah 15 bibit.

Data pengamatan yang diperoleh dianalisis dengan uji $\mathrm{F}$ (analisis varian). Apabila hasil uji $\mathrm{F}$ berbeda nyata maka dilanjutkan dengan uji jarak berganda Duncan (DMRT).

\section{HASIL DAN PEMBAHASAN}

Berdasarkan analisis ragam (Tabel 1) dapat diketahui bahwa penggunaan naungan memberikan pengaruh nyata terhadap pertumbuhan tinggi, diameter, dan indeks mutu bibit, tetapi tidak berpengaruh nyata terhadap persen hidupnya. 
Selanjutnya dari uji Duncan (Tabel 2), naungan dengan kerapatan $50 \%$ menghasilkan pertumbuhan tinggi $(21,90 \mathrm{~cm})$ dan diameter $(2,85 \mathrm{~mm})$ terbaik dibandingkan naungan lainnya. Nilai indeks mutu

Tabel 1. Analisis varian tinggi, diameter, indeks mutu bibit dan persen hidup M. tsiampca

\begin{tabular}{lcccccccc}
\hline \multirow{2}{*}{ Sumber Variasi } & \multicolumn{2}{c}{ Tinggi } & \multicolumn{2}{c}{ Diameter } & \multicolumn{2}{c}{ Indeks Mutu Bibit } & \multicolumn{2}{c}{ Persen hidup } \\
\cline { 2 - 10 } & F-hit & $\operatorname{Pr}<\mathrm{F}$ & F-hit & $\operatorname{Pr}<\mathrm{F}$ & F-hit & $\operatorname{Pr}<\mathrm{F}$ & F-hit & $\operatorname{Pr}<\mathrm{F}$ \\
\hline Naungan & $30,88^{*}$ & 0,000 & $4,54^{*}$ & 0,012 & $5,10^{*}$ & 0,014 & $1,63 \mathrm{tn}$ & 0,271 \\
\hline $\begin{array}{l}\text { Keterangan: } \\
*=\text { Berbeda nyata pada taraf uji 0,05 } \\
\text { tn = Tidak berbeda nyata pada taraf uji 0,05 }\end{array}$ & & & & & & & & \\
\end{tabular}

bibit terbaik dalam penelitian ini dihasilkan oleh perlakuan naungan dengan kerapatan $25 \%(0,15)$, namun secara statistik perlakuan ini tidak berbeda dengan perlakuan naungan dengan kerapatan $50 \%$ $(0,13)$.

Tabel 2. Uji Duncan tinggi, diameter, indeks mutu bibit dan persen hidup M. tsiampaca

\begin{tabular}{cccc}
\hline Perlakuan & $\begin{array}{c}\text { Tinggi } \\
(\mathrm{cm})\end{array}$ & $\begin{array}{c}\text { Diameter } \\
(\mathrm{mm})\end{array}$ & $\begin{array}{c}\text { Indeks } \\
\text { Mutu } \\
\text { Bibit }\end{array}$ \\
\hline Naungan $50 \%$ & $21,90 \mathrm{a}$ & $2,85 \mathrm{a}$ & $0,13 \mathrm{a}$ \\
Naungan $75 \%$ & $14,31 \mathrm{~b}$ & $2,23 \mathrm{~b}$ & $0,05 \mathrm{~b}$ \\
Naungan $25 \%$ & $9,04 \mathrm{c}$ & $2,28 \mathrm{~b}$ & $0,15 \mathrm{a}$ \\
\hline
\end{tabular}

Keterangan: Huruf yang berbeda menunjukkan berbeda nyata pada taraf uji 0,05

\section{Tinggi Tanaman}

Berdasarkan hasil percobaan dapat diketahui bahwa perbedaan naungan memberikan pengaruh nyata terhadap tinggi tanaman. Naungan dengan tingkat kerapatan $50 \%$ adalah perlakuan yang menghasilkan respon pertumbuhan tinggi tanaman cempaka wasian terbaik $(21,90 \mathrm{~cm})$. Sedangkan naungan dengan tingkat kerapatan $75 \%$ dan $25 \%$ menghasilkan respon pertumbuhan tinggi tanaman cempaka wasian sebesar $14,31 \mathrm{~cm}$ dan $9,04 \mathrm{~cm}$. Berdasarkan hasil tersebut dapat diketahui bahwa tingkat intensitas cahaya yang dapat memberikan respon tinggi bibit cempaka wasian secara optimal adalah naungan dengan Intesitas Cahaya (IC) sebesar \pm 19.100 lux. Dalam bukunya, Soekotjo (1976) menjelaskan bahwa pengaruh intensitas cahaya pada pembesaran sel dan diferensiasi sel memberikan pengaruh terhadap pertumbuhan tinggi, ukuran daun, serta batang tanaman.

Intensitas cahaya yang terlalu rendah (IC $<10.000$ lux) dan terlalu tinggi (IC>30.000 lux) menghasilkan respon pertumbuhan tinggi yang tidak optimal bagi bibit cempaka wasian. Cahaya merupakan elemen terpenting yang dibutuhkan tanaman dalam proses fotosintesis. Irwanto (2006) menyatakan bahwa semai yang berada di bawah naungan hidupnya akan tertekan" karena tidak mendapatkan sinar matahari yang cukup. Begitupun sebaliknya cahaya yang terlalu berlebihan juga akan berpengaruh terhadap pertumbuhan tinggi tanaman, karena pada titik jenuh cahaya, tanaman tidak mampu lagi menambah hasil fotosintesis walaupun jumlah cahaya yang tersedia meningkat. Guslim (2007) dalam penelitiannya menyampaikan bahwa pada tanaman tahan naungan akan mengalami penurunan kecepatan fotosintesis pada intensitas cahaya yang tinggi dikarenakan menutupnya mulut daun. Kramer dan Kozlowski (1979) juga menyatakan bahwa intensitas cahaya yang terlalu tinggi akan melemahkan kegiatan proses fotosintesis dan sementara itu laju respirasi meningkat. Intensitas cahaya yang tinggi kurang mendukung proses fotosintesis pada tanaman sehingga pertumbuhan tinggi tanaman menjadi rendah. Cahaya yang berlebihan dapat mengakibatkan terjadinya proses foto-oksidasi klorofil dan mengakibatkan kerusakan pada klorofil, sementara itu klorofil yang tersisa tidak mampu meyerap semua energi yang tersedia sehingga kegiatan fotosintesis menjadi semakin lemah (Kinho, 2013).

\section{Diameter Batang}

Pertumbuhan diameter tanaman cempaka wasian terbaik dalam penelitian ini dihasilkan oleh perlakuan dengan kerapatan naungan $50 \%(2,85 \quad \mathrm{~mm})$. Sedangkan perlakuan dengan kerapatan $75 \%$ dan $25 \%$ memiliki nilai pertumbuhan sebesar 2,23 mm dan 2,28 mm. Toumey dan Korstia (1974) dalam Simarangkir (2000) menyatakan bahwa pertumbuhan diameter tanaman berhubungan erat dengan laju fotosintesis dan sebanding juga dengan jumlah intensitas cahaya matahari yang diterima dan respirasi. Total luas daun aktif dalam tanaman yang dapat melakukan fotosintesis akan berpengaruh terhadap produk fotosintesis yang akan dihasilkan. Kondisi pertumbuhan daun cempaka wasian pada perlakuan dengan kerapatan naungan $50 \%$ cenderung lebih baik 
jika dibandingkan dengan perlakuan lainnya. Pada perlakuan ini, daun yang dihasilkan memiliki kecenderungan panjang dan lebar yang lebih besar. Rata-rata panjang dan lebar daun bibit cempaka wasian pada perlakuan dengan kerapatan naungan $50 \%$ adalah $6,34 \mathrm{~cm}$ dan $2,96 \mathrm{~cm}$, sedangkan pada perlakuan dengan kerapatan naungan $25 \%$ memiliki panjang dan lebar daun sebesar $5,44 \mathrm{~cm}$ dan $2,12 \mathrm{~cm}$. Marjenah (2001) mengemukakan bahwa jumlah daun tanaman lebih banyak di tempat ternaung daripada di tempat terbuka. Pada tempat terbuka daun mempunyai kandungan klorofil lebih rendah dari pada tempat ternaung. Naungan memberikan efek yang nyata terhadap luas daun. Daun memiliki permukaan yang lebih besar di bawah naungan daripada di tempat terbuka.

Secara umum, respon adaptif tanaman terhadap intensitas cahaya yang optimal adalah dengan peningkatan rasio luas daun, kandungan klorofil, bobot daun terhadap batang, dan panjang batang. Dengan kata lain, respon tersebut adalah meliputi penurunan ketebalan daun, rasio klorofil-a dengan klorofil-b, dan rasio pertumbuhan relatif akar terhadap tajuk (Fujita et al., 1993 ). Sebaliknya daun-daun pada tanaman terbuka (tidak ternaungi) umumnya lebih kecil, lebih tebal, dan menyerupai kulit dibandingkan dengan tanaman yang ternaungi (Daniel et al., 1992). Akibat dari adaptasi tersebut adalah bibit akan mengalami pertumbuhan yang lebih maksimal pada organ batangnya dibandingkan organ lainnya. Hal ini juga terjadi pada bibit cempaka wasian yang dicobakan. Pada perlakuan dengan kerapatan naungan $25 \%$ diketahui menghasilkan pertumbuhan diameter yang lebih baik jika dibandingkan dengan perlakuan kerapatan dengan naungan $75 \%$ meskipun memiliki pertumbuhan tinggi yang paling kecil jika dibandingkan perlakuan lainnya. Hal ini juga sesuai dengan pendapat Marjenah (2001) yang mengemukakan bahwa pada intensitas cahaya yang cukup tanaman cenderung memacu pertumbuhan diameternya sehingga tanaman yang tumbuh pada tempat terbuka mempunyai tendensi untuk menjadi pendek dan kekar.

Pertumbuhan diameter bibit cempaka wasian terendah dalam penelitian ini dihasilkan oleh perlakuan dengan kerapatan tertinggi $(75 \%)$. Sama halnya dengan cahaya yang berlebihan, kurangnya cahaya yang diterima oleh tanaman juga sangat berpengaruh terhadap pertumbuhan organ yang dimilikinya. Daniel et al. (1992) menyatakan bahwa terhambatnya pertumbuhan diameter tanaman dikarenakan produk fotosintesisnya serta spektrum cahaya matahari yang kurang merangsang aktivitas hormon dalam proses pembentukan sel meristematik ke arah diameter batang.

\section{Indeks Mutu Bibit (IMB)}

Indeks mutu bibit merupakan salah satu indikator tingkat kesiapan bibit untuk dipindahkan dari persemaian ke lapangan (penanaman). Hendromono dan Durahim (2004) mengemukakan bahwa bibit yang memiliki nilai IMB minimal 0,09 akan memiliki daya tahan hidup yang tinggi apabila dipindah ke lapangan. Dalam penelitian ini, hanya bibit dengan perlakuan tingkat kerapatan naungan $75 \%$ yang memiliki nilai IMB $<0,09$ yaitu 0,05 . Sedangkan bibit dengan perlakuan tingkat kerapatan naungan $25 \%$ dan $50 \%$ memiliki nilai IMB sebesar 0,15 dan 0,13.

Perhitungan nilai indeks mutu bibit sangat erat kaitannya dengan berat kering bibit, baik yang berada di atas tanah (batang dan daun) maupun organ tanaman yang terdapat di dalam tanah (akar). Prawiranata et al. (1995) menyatakan bahwa berat kering bibit merupakan suatu indikator untuk menentukan baik tidaknya bibit dikarenakan berat kering mencerminkan status nutrisi tanaman. Pertumbuhan akar pada bibit cempaka wasian yang dicobakan dalam penelitian ini memiliki perbedaan yang cukup signifikan. Berdasarkan nilai rata-rata berat kering akar diketahui bahwa berat kering akar terendah ditunjukkan oleh perlakuan dengan kerapatan naungan $75 \%$ (0,12 gr), sedangkan berat kering akar untuk perlakuan naungan $25 \%$ dan $50 \%$ secara berurutan adalah 0,33 gr dan 0,34 gr. Berdasarkan hasil ini dapat diketahui bahwa selain mengalami pertumbuhan yang lebih cenderung pada organ batang, bibit cempaka wasian pada perlakuan dengan kerapatan naungan rendah $(25 \%)$ juga mengalihkan pertumbuhannya pada organ akar.

Perlakuan dengan kerapatan naungan $25 \%$ merupakan perlakuan yang menghasilkan nilai IMB tertinggi, namun secara statistik nilainya tidak berbeda (sama) dengan perlakuan dengan tingkat kerapatan naungan $50 \%$. Secara umum besar kecilnya niali IMB dipengaruhi oleh besaran cahaya yang diterima oleh tanaman. Lebih lanjut Wardiana dan Herman (2009) juga menyatakan bahwa fotosintat yang dihasilkan dari proses fotosintesis sebagian disimpan dalam jaringan tanaman dan sebagian lagi digunakan sebagai energi kimia untuk menyokong pertumbuhan dan perkembangan tanaman. Jumlah simpanan fotosintat ini salah satu indikatornya adalah dicerminkan dalam bentuk bobot kering dan bobot basah tanaman. 


\section{Persen Hidup Tanaman}

Persen hidup tanaman sangat erat kaitannya dengan kemampuan suatu jenis tanaman untuk berinteraksi dengan kondisi lingkungan tempat tumbuh. Berdasarkan hasil analisis dapat diketahui bahwa perbedaan tingkat kerapatan naungan yang diberikan terhadap bibit cempaka wasian tidak berpengaruh terhadap persen hidupnya. Hal ini mengindikasikan bahwa pada rentang intensitas cahaya \pm 8.018 lux hingga \pm 37.350 lux, bibit cempaka wasian masih dapat bertahan hidup $( \pm 88 \%)$, tetapi akan mengalami pertumbuhan yang berbeda-beda pada tiap tingkatan naungannya.

\section{KESIMPULAN}

Perlakuan dengan tingkat kerapatan naungan 50 $\%$ (Intensitas cahaya \pm 19.100 lux) memberikan pengaruh terbaik dalam pertumbuhan dan mutu bibit cempaka wasian di persemaian.

\section{SARAN}

Dalam upaya perbanyakan bibit cempaka wasian, perlu diperhatikan pemberian naungan sebagai kontrol cahaya masuk sehingga pertumbuhan dan mutu bibit dapat diperoleh yang terbaik.

\section{UCAPAN TERIMA KASIH}

Ucapan terima kasih kami sampaikan kepada Bapak Sarwidi, SP selaku Manajer Persemaian Permanen BPDAS Tondano, Eki Kaeng, Daud, dan Ruly Said, selaku pegawai teknis persemaian permanen yang telah banyak memberikan bantuan dan masukan selama pelaksanaan kegiatan penelitian ini hingga selesainya penulisan naskah.

\section{DAFTAR PUSTAKA}

Daniel T. W, Helms, J. A. and. Baker, F. S. (1992). PrinsipPrinsip Silvikultur (Terjemahan). Yogyakarta: Gadjah Mada University Press.

Fujita, K., Matsamoto, K., Buda, G. K. O., and Ogata, S. S. (1993). Effect of shading on growth and Dinitrogen fixation of Kudzce and tropical pasture legumes. Soil Sci. Plant Nutr., 39(1), 43 - 54.

Guslim. (2007). Agroklimatologi. Medan (ID): USU Pr. [Kemenristek] Kementerian Negara Riset dan Teknologi Republik Indonesia. 2006. Indonesia 2005 - 2025 Buku Putih Penelitian, Pengembangan, Penerapan Ilmu Pengetahuan dan Teknologi Bidang Ketahanan Pangan. Jakarata (ID): Kemenristek.

Hani, A. (2009). Pengaruh media tanam dan empat intensitas naungan pada pertumbuhan bibit Khaya antotecha. Tekno Hutan Tanaman, 2(3), 99 - 105.

Hendromono. (1994). Pengaruh media organik dan tanah mineral terhadap mutu bibit Pterygota alata Roxb. Buletin Penelitian Hutan, 617, 55-64.
Hendromono dan Durahim. (2004). Pemanfaatan limbah sabut kelapa sawit dan sekam padi sebagai medium pertumbuhan bibit mahoni afrika (Khaya anthoteca. C.DC). Buletin Penelitian Hutan, 644. Bogor: Badan Litbang Kehutanan. Puslitbang Hutan dan Konservasi Alam.

Irwanto. (2006). Pengaruh Naungan Terhadap Pertumbuhan Semai Shorea sp. di Persemaian. Thesis tidak diterbitkan, Pasca Sarjana Universitas Gajah Mada, Yogyakarta.

Kinho, J. (2013). Pengaruh naungan dan aplikasi mulsa organik terhadap pertumbuhan eboni (Diospyros Rumpii Bakh) di Hutan Penelitian Batuangus. Prosiding Seminar Nasional Silvikultur 1 (pp. 298 306). Makassar.

Kinho, J. (2010). Prospek Pengembangan Cempaka di Sulawesi Utara. Sintesis Hasil Penelitian Hutan Tanaman, 375 - 378.

Kinho, J dan Irawan, A. (2011a). Studi keragaman jenis cempaka berdasarkan karakteristik morfologi di Sulawesi Utara. Prosiding Ekspose Hasil-Hasil Penelitian (pp. 61 - 78). Manado: Balai Penelitian Kehutanan

Kinho, J. dan Mahfudz. (2011b). Prospek Pengembangan Cempaka di Sulawesi Utara. Balai Penelitian Kehutanan Manado

Kramer P. J. and. Kozlowski, T. T. (1979). Physiology of Woody Plants. Florida: Academic Press, Inc.

Kurniaty, R., Budiman, B., dan Suartana, M., (2010). Pengaruh media dan naungna terhadap mutu bibit suren (Toona sureni MERR.). Jurnal Penelitian Hutan Tanaman, 7(2), 77 - 83.

Langi, Y. A. R. (2007). Model Penduga Biomassa dan Karbon pada Tegakan Hutan Rakyat Cempaka (Elmrerillia ovalis) dan wasian (Elmerrillia celebica) di Kabupaten Minahasa Sulawesi Utara. Thesis tidak diterbitkan, Pasca Sarjana Institut Pertanian Bogor, Bogor

Lawe, Z., Kalangi, J. I., Thomas, A., Rombang, J. A. (2012). Studi Riap Cempaka Magnolia tsiampaca (Miq.) Dandy di Pinaras dan Masarang. ejournal.unsrat.ac.id. Diakses tanggal 17 Desember 2014.

Marjenah, (2001). Pengaruh perbedaan naungan di persemaian terhadap pertumbuhan dan respon morfologi dua jenis semai meranti. Jurnal Ilmiah Kehutanan "Rimba Kalimantan", 6(2).

Prawiranata, Harran, W., Tjondronegoro, S. (1995). DasarDasar Fisiologi Tumbuhan Jilid II. Bogor: Departemen Botani. Fakultas MIPA IPB.

Simarangkir, B. D. A. S. (2000). Analisis riap Dryobalanops lanceolata Burck pada lebar jalur yang berbeda di hutan koleksi Universitas Mulawarman Lempake. Frontir, 32.

Soekotjo, W. (1976). Silvika. Proyek Peningkatan/Pengembangan Perguruan Tinggi. Fakultas Kehutanan IPB. Bogor.

Wardiana, E. dan Herman, M. 2009. Pengaruh naungan dan media tanam terhadap pertumbuhan bibit kemiri sunan (Reutealis triperma (BLANCO)) Airy Shaw. Buletin RISTRI, 1(4), 197 - 205 
Jurnal WASIAN Vol.4 No.1 Tahun 2017:11-16 